\title{
Somatic heterosis signs root system in Arabidopsis thaliana (L.) Heynh
}

\begin{abstract}
The characteristics of inheritance signs in Arabidopsis root system at interaction genes ETR 1 and ETR 2 are studied. It is stated, that at crossing plants of mutant lines Etr1-1 and Etr2-1 polymeric interaction of genes ETR 1 and ETR2 takes place. In that case splitting in $\mathrm{F}_{2}$ occurs in ratio 9:6:1. In hybrids of first generation the somatic heterosis is observed, that becomes apparent in more vigorous development of side roots in comparison with primary forms. In $\mathrm{F}_{1}$ on genes ETR 1 and ETR2 in each alleles pair the domination of mutant gene over wild type gene $($ ETR $1<$ Etr $1-1$ ETR2 $<$ Etr $2-1)$ occurs. In hybrid plants of first generation the additive effect of non-alleles, dominating mutant genes Etr1-1 and Etr2-1 is observed. In the second generation the process of splitting hybrids is going on, their superiority over parental forms as to the length of side roots decreases. It has to do with shortening heterozygosity of plants in the generation $\mathrm{F}_{2}$
\end{abstract}

Keywords: arabidopsis thaliana (L.) heynh, root system, gene, mutation, gene interaction, heterosis
Volume 5 Issue 3 - 2018

\author{
Sergei Hablak,' Riabovol laroslav ${ }^{2}$ \\ 'Agroprom Holding "Kernel", Ukraine \\ ${ }^{2}$ Uman National University of Horticulture, Ukraine
}

Correspondence: Sergei Hablak, Agroprom Holding "Kernel", STU “Friendship-Nova, Str. Komarova, 59, town. Varva, Varvinsky district, Chernihiv region, Ukraine, 17600 , Email serhab211981@yandex.ua

Received: September 21, 2017 | Published: May 30, 2018

\section{Introduction}

Heterosis is a complicated and very important for evolution and selection phenomenon of increasing energy, vital activity and productivity of first generation hybrids $\left(\mathrm{F}_{1}\right)$ in comparison with parental forms. ${ }^{1}$ The American genetic W. Shall introduced first the notion of heterosis in $1914 .^{2}$ Last year's heterosis was found out in lots of plants, animals and microorganisms.$^{3-5}$ However, the question about mechanism of heterosis stays still an unsolved problem of genetics.

At present, the explanation of heterosis reasons is as two main hypotheses-domination and super domination. As to domination hypothesis, heterosis is related with three effects of dominating genes action: suppressing harmful recessive alleles, additive effect and nonallele complementary interaction. ${ }^{2}$ The super domination hypothesis explains the effect of heterosis as an interaction between dominant and recessive alleles of the same gene. ${ }^{1}$

Unfortunately, no one of these hypotheses is able to explain fully the nature of heterosis. Last time many authors are coming round to the opinion that it is more correctly to view the hypothesis of domination and super domination as the compounds of one genetic theory of heterosis ${ }^{2}$ is obvious, that conclusion about genetic mechanisms of heterosis should be made only after the picture of gene interaction on the biochemical and molecular levels is clear. Last time it becomes clearer, that on the problem of heterosis mechanism we should return to the detailed analyzing of genetics of signs. Comparatively lately in A. thaliana several dominant mutations were received. Here are mutations Etr1-1, Etr2-1 on genes ETR1, ETR2.

Genes ETR1, ETR2 code the receptor Hystidyncynases ETR1, ETR2 responsible for perception and transfer into the plant cell the signal, generated by ethylene. ${ }^{6}$ Mutation Etr1-1, Etr2-1in these genes cause lesions of membrane receptors, through which the reaction of plants on ethylene manifests. ${ }^{7}$ Ethylene $\left(\mathrm{C}_{2} \mathrm{H}_{4}\right)$ is phyto hormone inhibitor, which is formed in plants and in the lowest concentrations; it regulates the most important programs of their life. ${ }^{8}$ The peculiarity of ethylene is that in contrast to other hormones it does not come from one organ into another, acting as distance signal. Instead of ethylene its predecessor (ACC) moves through the plant and namely it takes part in transferring the signal. Ethylene itself coming out of the plant may provide signalization among plants. ${ }^{9}$

Ethylene influences on many aspects of plants life. It inhibits cell division, hinders the polar transport of auxin, causes obsolescence of leaves and flowers, increases fruit ripening and abscission, takes part in the plant answer on different stress factors, among them inhibits root growth in the root system, but facilitates the formation of additional roots on the stem. ${ }^{6}$ In the genome $A$. thaliana were detected five genes (ETR1, ETR2, EIN4, ERS1 and ERS2), coding the sensor histidine kinases, which are receptors for ethylene. These genes are a part of a small gene family of ethylene signal proteins-receptors. ${ }^{10}$

The receptor histidine kinase ETR1, ETR2, EIN4, ERS1 and $E R S 2$ consist of a tying ethylene integral domain containing three transmembrane parts and GAF-domen placed in cytoplasm, responsible for forming of intermolecular complexes and histidine kinases domain. Proteins-receptors ETR1, ETR2, EIN4, ERS1 and $E R S 2$ also have a sizeable C-terminus perceiving domain, which is a typical functional module in the receptor histidine kinase of bacteria and serves for delivery transphosphorilation reaction. In receptors ETR1, ETR2, EIN4, ERS1 and ERS2 histidine kinase domain has fermentative activity. ${ }^{11}$

Mutations on genes ETR1, ETR2, EIN4, ERS1 and ERS2 cause lesions of membrane receptors through which the reaction of plants on ethylene manifests. The treatment these mutant plants with ethylene does not give the typical answer of germs to $\mathrm{C}_{2} \mathrm{H}_{4}$ : unlike the wild type the growth of stem, its thickening, inhibition root growth do not stop in them. Ethylene does not cause the activation ethylene sensitive genes in these mutants. ${ }^{12}$ The ways of perceiving ethylene in plants are duplicated by several receptors, so it is rather difficult to get plants non-sensitive to it. It is necessary then for a plant to be mutant on 4-5 locus simultaneously. ${ }^{13}$ 
It is universally recognized that dominating mutations are characterized by inhibition the manifestation of wild type genes under heterozygous condition. ${ }^{1}$ In case, they have advances of economic importance, the first generation hybrids may manifest heterosis. Taking into account the uncertainty of the matter of participating dominating mutations in heterosis, the object of this work was to study inheritance signs in Arabidopsis root system at interaction genes ETRland ETR2.

\section{Materials and methods}

As material for research the plants Arabidopsis thaliana (L.) Heynh. ecotype Columbia (Col-O) and mutant lines Ethylene-resistant1-1 (Etr1-1), Ethylene-resistant2-1 (Etr2-1) were selected. The seeds of mutant lines were got from Nottinghem centre of Arabidopsis samples (Nottingham Arabidopsis Stock Centre (NASC), UK).

The plants were grown in the laboratory on the aseptic vitro culture on the agar nutrient medium of Knopp, enriched with microelements. ${ }^{14}$

The seeds were prepared by vernalization for five days at the temperature $4-6^{\circ} \mathrm{C}$ and the following one-day germination at the room temperature. Test tubes were wrapped in two layers of paper protecting roots from heat and light. The plants were cultivated at the temperature $18-20^{\circ} \mathrm{C}$, by the whole day lighting $4000-7000$. Castration and compulsory hybridization were conducted under the microscope of type MBS-9. Genetic analyzing as to of inheritance signs of root system was conducted in $\mathrm{F}_{1}, \mathrm{~F}_{2}$. The capacity of selection in the second generation was 186 plants. Observing the plants, we guided general methodic of vegetation and comparative morphologic research. ${ }^{15}$ Mathematic results processing was conducted on methods, described by Dospekhov ${ }^{15}$ and Lakin ${ }^{16}$

\section{Results}

In plants $A$. thaliana roots are able to branching. Branching provides the great increasing their general absorbing area. Usually Arabidopsis plants spread in the nature form the root system with many and much branched roots.

In A. thaliana the plants of some mutant lines Etr1-1 and Etr2-1, with dominant mutations in their genotype, possess greater branching degree comparatively with the wild types. Several different genes Table 1 Mean values of biometric parameters signs of root system ecotype Col-O, parental forms (Etr1-1, Etr2-1) and hybrids $\mathrm{F}_{1}$ and $\mathrm{F}_{2}$ in the budding phase (30 day after germination) determine it. Therefore, typical length of side roots of the main one, typical for the natural plants, is determined by the normal genes ETR1 and ETR2; the increased one is determined by the mutant genes Etr1-1 and Etr2-1, which are dominant related to the wild type genes.

It is the well-known fact, that there are no significant differences between the genes of the wild type and the mutant genes. The genes inherent to the wild forms of plants also were mutant at their time. In the evolution process, they were selected by the natural selection, as they developed qualities and properties best favorable for the species existence. At crossing of mutant lines of plants Etr1-1 and Etr 2-1 all first generation of hybrids ETR1 Etr1-1 ETR2 Etr2-1 consisted of plants with greater length of side roots of different branching orders in comparison with the parental forms (Table 1). We observed the somatic heterosis; it manifested in the greater development of the side roots in comparison with the primary forms. In $\mathrm{F}_{1}$ on genes ETRI and ETR2 in each allele pair domination of the mutant gene over the wild type gene occurred. (ETR1<Etr1-1 ETR2<Etr2-1). Besides, in hybrid plants of the first generation we observed the additive effect of non -allele dominant mutant genes Etr1-1 and Etr2-1.

In the second generation of plants the splitting on phenotype occurred in such ratio: the maximal length of side roots was in 103 plants, the middle growth of side roots was in 75 plants, short side roots were in 8 plants (Table 2). In this case, the length of side roots in the hybrids of the second generation depended on the presence of two different dominant mutant alleles Etr1-1 and Etr2-1 or one of them independent Etr1-1 or Etr2-1. Therefore, dominant mutant gene Etr11 and Etr2-1 effected additively the sign, namely cumulative effect. The splitting in $\mathrm{F}_{2}$ occurred in the ratio 9:6:1. We can explain the results by polymer action of ETR 1 and ETR 2 genes on the development of the sign: "The length of the side roots".

It is known, that the polymer interaction of genes is common for all quantitative signs. It can be with the full domination and nonfull domination. Usually we observe the splitting at the non-full domination. When the domination is non-full, uninterrupted variation of signs is going on in the ratio $1: 4: 6: 4: 1{ }^{2,3}$ When the domination is full splitting occurs in the ratio $9: 6: 1$. We observe it at clarification the character of genes ETR1 and ETR2 effect on the root system signs.

\begin{tabular}{|c|c|c|}
\hline \multirow{3}{*}{ Line designation } & \multicolumn{2}{|l|}{ The type of roots } \\
\hline & \multicolumn{2}{|c|}{ The side roots of the main root } \\
\hline & Quantity of roots & The length of roots $\mathrm{mm}$ \\
\hline WT (Col-0) & 29,6 & 12,5 \\
\hline maternal form Etr $1-1$ & 45,0 & 22,4 \\
\hline paternal form Etr2-1 & 46,0 & 23,3 \\
\hline hybrids $\mathrm{F}_{1}$ & 66,1 & 35,7 \\
\hline \multicolumn{3}{|l|}{ hybrids $\mathrm{F}_{2}$} \\
\hline $\begin{array}{l}\text { ETR1 Etr1-1 ETR2 Etr2-1, ETR1 Etr1-1 Etr2-1 Etr2-1, } \\
\text { Etr1-1 Etr1-1 ETR2 Etr2-1, Etr1-1 Etr1-1 Etr2-1 Etr2-1 }\end{array}$ & 65,6 & 35,4 \\
\hline $\begin{array}{l}\text { ETR1 ETR1 ETR2 Etr2-1, ETR1 Etr1-1 ETR2 ETR2, } \\
\text { ETR1 ETR1 Etr2-1 Etr2-1, Etr1-1 Etr1-1 ETR2 ETR2 }\end{array}$ & 43,2 & 22,2 \\
\hline ETR1 ETR1 ETR2 ETR2 & 28,7 & 12,8 \\
\hline $\mathrm{HCP}_{05}$ & 3,0 & 2,6 \\
\hline
\end{tabular}


Table 2 Splitting in generation F2 on genes ETR1 and ETR2

\begin{tabular}{|c|c|c|c|c|}
\hline Designation & $\begin{array}{l}\text { ETR1 Etr1-1 ETR2 Etr2-1, ETR1 } \\
\text { Etr1-1 Etr2-1 Etr2-1, Etr1-1 Etr1-1 } \\
\text { ETR2 Etr2-1, Etr1-1 Etr1-1 Etr2-1 } \\
\text { Etr2-1 }\end{array}$ & $\begin{array}{l}\text { ETR1 ETR1 ETR2 Etr2-1, ETR1 } \\
\text { Etr1-1 ETR2 ETR2, ETR1 ETR1 } \\
\text { Etr2-1 Etr2-1, Etr1-1 Etr1-1 ETR2 } \\
\text { ETR2 }\end{array}$ & $\begin{array}{l}\text { ETR1 ETR1 ETR2 } \\
\text { ETR2 }\end{array}$ & Total \\
\hline$f$ & 103 & 75 & 8 & 186 \\
\hline$f^{1}$ & 104 & 70 & 12 & 186 \\
\hline$d$ & -1 & 5 & -4 & \\
\hline$d^{2}$ & 1 & 25 & 16 & \\
\hline$\chi^{2}$ & 0,01 & 0,36 & 1,33 & 1,7 \\
\hline
\end{tabular}

\section{Discussion}

The obtained results of study talk us over to the hypothesis of dominating in the heterosis mechanism, which G. Davenport hypothesized primarily in 1908 and the American genetic D. Johnes formulated fully and convincingly its main ideas in 1917. The perceptions that domination appears in the process of evolution build the basics of the hypothesis; genes, which are favorable for the growth and development of organism, become dominant and half-dominant and genes, which are not favorable become recessive. According this hypothesis is related with multisided action of dominant genes. ${ }^{2}$

In our case, the analysis of the inheritance in the Arabidopsis root system the length of the side roots at the interaction of genes ETRI and ETR2 has shown that mutant genes, which improve some useful signs and abilities, are able to become dominant alleles. In this they suppress the wild type genes and in the case of their positive influence on the same quantitative signs, act additively on their manifestation. It argues a lot in favor of dominant mutations in the appearance of heterosis. The most important arguments are the following ones.

First, in Drosophila, Man, other animal and plants many examples of dominant mutations are known, where the new sign is manifested already in heterozygotes. One of such examples in Man is a gene that can course brachidaktilia. The carriers of such dominant signs are usually heterozygote and transfer this sign to the half of their offspring approximately. ${ }^{17}$

Second, the transition of an allele from the recessive to the dominant condition can be caused by different mechanisms acting on different levels of transforming of inherited information in ontogenesis. Genetically the transition can be reached through the selection of the special genes-modificators, effecting the phenotypic manifestation of the mutant allele (R. Fisher's hypothesis) or through the selection alleles with greater physiological activity (providing more intensive enzymes synthesis), than primary recessive variant (S. Raits's and D. Holdain's hypothesis). ${ }^{18}$

Anyway, the level of domination phenotypic manifestation of alleles can evolve, raising over the selection control, if the allele becomes favorable for the carrier at the change of external conditions. The example of it is the raising of domination allele, controlling the dark color in the peppered moth, which according to the data occurred during the last century in the industrial regions of the Europa. ${ }^{18}$

Third, the heterosis does not manifest at each crossing in $F_{1}$ plants. If the heterosis were conditional upon the simple dominant allele number, which are in the population, that number could be easily combined through the line of crossings and to get heterosis combinations. ${ }^{19}$ It is known, that one of the important points in the study of heterosis mechanism problem, is the question of what genes provide might development of the first generation hybrids.
Deep scientific analyzing of heterosis event in the second half of the twenties century showed that pees, corn, sugar beet, fodder beet, sorgo and other crops have not much sources for the great combination ability. In particular, the results of large-scale selections for combination ability, concerned, for example thousands of lines in corn and lasting more than 50 years, let us suppose that there are not less than ten sources, carrying genes with great combination activity. The analyzing of genealogical lines, determining the high combination ability shows, that in their basis there are not more, than ten source materials. It makes reconceptualize the nature of the heterosis. ${ }^{20}$

Unfortunately, the question what genes in a heterozygote condition course the hybrids $F_{1}$ surpass the parental forms on the number of signs stays not clarified. Many scientists studied dependence between the crop capacities of self-pollinated lines and their crossed hybrids. At the same time the clear relationship between the hybrid productivity and the lines completing them was not stated. ${ }^{2}$ In this connection, the researchers have to conduct the complicated work creating inbred lines and evaluating their combining ability.

However, now from our conducted research, it becomes clear, that among the cultured forms and their relatives we should search for dominant mutations (dominant mutant genes), leading to the improvement of one or another sign or property. It is possible that a part of hybrids, sorts of plants and species of animals were bred by crossing lines with a number of favorable dominant mutant alleles. Obviously, a very rare appearance of dominant mutations in comparison with recessive mutations does not give the possibility to find in plants a big amount of sources with genes of high combining ability in their genotype, which allow getting the high heterosis hybrids when crossing.

\section{Acknowledgement}

None.

\section{Conflict of interest}

The authors declare no conflict of interest. This article does not contain any studies with human participants or animals performed by any of the authors.

\section{References}

1. Glazko VI, Glazko GV. Glossary of terms in applied genetics and DNA technology. K: IAB; 1999.

2. Gulyaev GV. Genetics. Moscow: Kolos; 1984

3. Lobashev ME. Genetics. Saint Petersburg: Publishing House of Leningrad State University; 1985.

4. Barth S, Busimi AK, Friedrich Utz H, et al. Heterosis for biomass yield and related traits in five hybrids of Arabidopsis thaliana $\mathrm{L}$. Heynh. Heredity (Edinb). 2003;91(1): 36-42. 
5. Yang $M$, Wang X, Ren D, et al. Genomic architecture of biomass heterosis in Arabidopsis. PNAS. 2017;114 (30): 8101-8106.

6. Johnson PR, Ecker JR. The ethylene gas signal transduction pathway: a molecular perspective. Annu Rev Genet. 1998;32:227-254.

7. Chang C, Kwok SF, Bleecker AB, et al. Arabidopsis ethyleneresponse gene ETR1: similarity of product to two-component regulators. Science. 1993;262(2):539-544.

8. Kulaieva ON. As regulated by the plant life. Soros Educational Journal. 1995;1:2-27.

9. Kulaieva ON. Ethylene in Plant Life. Sorosovksy Obrazovatelny Zhurnal. 1998;11:78-84.

10. Liu Q, Xu C, Wen CK. Genetic and transformation studies reveal negative regulation of ERS1 ethylene receptor signaling in Arabidopsis. BMC Plant Biol. 2010;10(2):60-64.

11. Hua J, Chang C, Sun Q, et al. Ethylene insensitivity conferred by Arabidopsis ERS gene. Science. 1995;269(5231):1712-1714.

12. Xiang Qu, Brenda P Hall, Zhiyong Gao, et al. A strong constitutive ethylene-response phenotype conferred on Arabidopsis plants containing null mutations in the ethylene receptors ETR1 and ERS1. BMC Plant Biol. 2007;15(7):3-7.

13. Moussatche P, Klee HJ. Autophosphorylation activity of the Arabidopsis ethylene receptor multigene family. J Biol Chem. 2004;279(47):48734-48741.

14. Rubin BA, Chernavina IA, Potapov NG. Large Practical Course on Physiology of Plants. Moscow: Vishay Shkola; 1978.

15. Dospekhov BA. Field Experience Method. Moscow: Agropromizdat; 1985

16. Lakin G.F. Biometrics. M: Executive Wk; 1990.

17. Muntzing A. Genetic studies. M: Foreign Literature Publishing House; 1963.

18. Ayala F, Kyger J. Modern genetics. M: World; 1988.

19. Abramova ZV. Workshop on genetics. L: Agropromizdat; 1992.

20. Shymnui VK. Problems of plant genetics. Herald VOGiS. 2004;8 (2):32-39. 